\title{
Attitudes towards Wildlife Consumption inside and outside Hubei Province, China, in Relation to the SARS and COVID-19 Outbreaks
}

\author{
Shuchang Liu ${ }^{1} \cdot{\text { Zheng Feei } \mathrm{Ma}^{2} \text { (D) } \cdot \text { Yutong Zhang }}^{3} \cdot$ Yingfei Zhang $^{4}$ \\ Accepted: 3 November 2020 / Published online: 11 November 2020 \\ (C) Springer Science+Business Media, LLC, part of Springer Nature 2020
}

\begin{abstract}
We designed a self-administered 20-item questionnaire to determine changes in attitudes towards wildlife consumption in Chinese adults during the SARS epidemic in 2002-2003 and on-going COVID-19 pandemic that was first identified in December 2019. A total of 348 adults ( 177 males and 171 females) with a mean age of $29.4 \pm 8.5$ years participated, the majority (66.7\%) from Hubei. The percentages of participants who had eaten wildlife significantly decreased from $27.0 \%$ during SARS to $17.8 \%$ during COVID-19 $(P=0.032)$. The most common reason participants provided for consuming wildlife was to try something novel (64.9\% during SARS and 54.8\% during COVID-19). More than half of participants ( $\geq 53.5 \%)$ reported that they had stopped eating wildlife meat because most species of wildlife are legally protected. Our study results indicate over the period between the SARS epidemic to the outbreak of the COVID-19 pandemic, attitudes towards the consumption of wildlife in China have changed significantly.
\end{abstract}

Keywords Wildlife consumption $\cdot$ Wet markets $\cdot$ Ecology $\cdot$ COVID-19 $\cdot$ SARS $\cdot$ Hubei Province, China

\section{Introduction}

In November 2002, an epidemic of severe acute respiratory syndrome (SARS) centred in Foshan municipality, Guangdong Province, was identified, which peaked in February 2003 (Evans et al. 2003). Early cases reported that patients positive for SARS lived near animal markets, and nearly half of them were food practitioners who had contact with animal products. After 17 years, in December 2019, a novel coronavirus pneumonia outbreak was reported in Wuhan, Hubei Province (Fig. 1). The coronavirus disease 2019 (COVID-19) outbreak was traced to the Huanan seafood market, and most of the early diagnosed patients had been to the local fish and wildlife market before the outbreak (Lu et al.

Zheng Feei Ma

Zhengfeei.Ma@xjtlu.edu.cn

1 School of Biosciences, University of Nottingham, Loughborough LE12 5RD, UK

2 Department of Health and Environmental Sciences, Xi' an Jiaotong-Liverpool University, Suzhou 215123, Jiangsu, China

3 Jinzhou Medical University, Jinzhou 121001, Liaoning, China

4 Mathematics Teaching and Research Office, Public Basic College, Jinzhou Medical University, Jinzhou 121001, Liaoning, China
2020). The fish and wildlife market also sold live animals such as poultry, bats, marmots, hedgehogs, badgers, birds, and snakes (Lu et al. 2020; Wu et al. 2020). Since both outbreaks have been linked to wildlife markets ( $\mathrm{Li}$ and Davey 2013; Lu et al. 2020; Wu et al. 2020), it is important to explore the changes of attitude towards eating wildlife before and after the two outbreaks in the general population.

Both the SARS and the on-going COVID-19 outbreaks have had extremely negative impacts worldwide. The World Health Organization (WHO) recorded $>8400$ cases of SARS and 800 deaths worldwide (Zhong et al. 2003). The COVID-19 outbreak has also led to serious consequences including unprecedented levels of infection and deaths, decreased quality of life, and increased stress due to strict lockdowns and limits on social interactions (Cao et al. 2020; Ma et al. 2020; Zhang and Ma 2020a,b). In mainland China, the number of diagnosed patients from 21st January 2020 until 2nd February 2020 increased from 330 cases to 17,000 cases within two weeks (Dong et al. 2020). Hubei Province, and especially its capital city Wuhan, have been significantly affected since Wuhan was the epicentre of the COVID-2019 outbreak. The total number of COVID-19 cases in Hubei Province had reached 67,800 as of March 28th. Meanwhile, the total number of COVID-19 cases in other Chinese provinces had reached 13,600 (Maier and Brockmann 2020). 


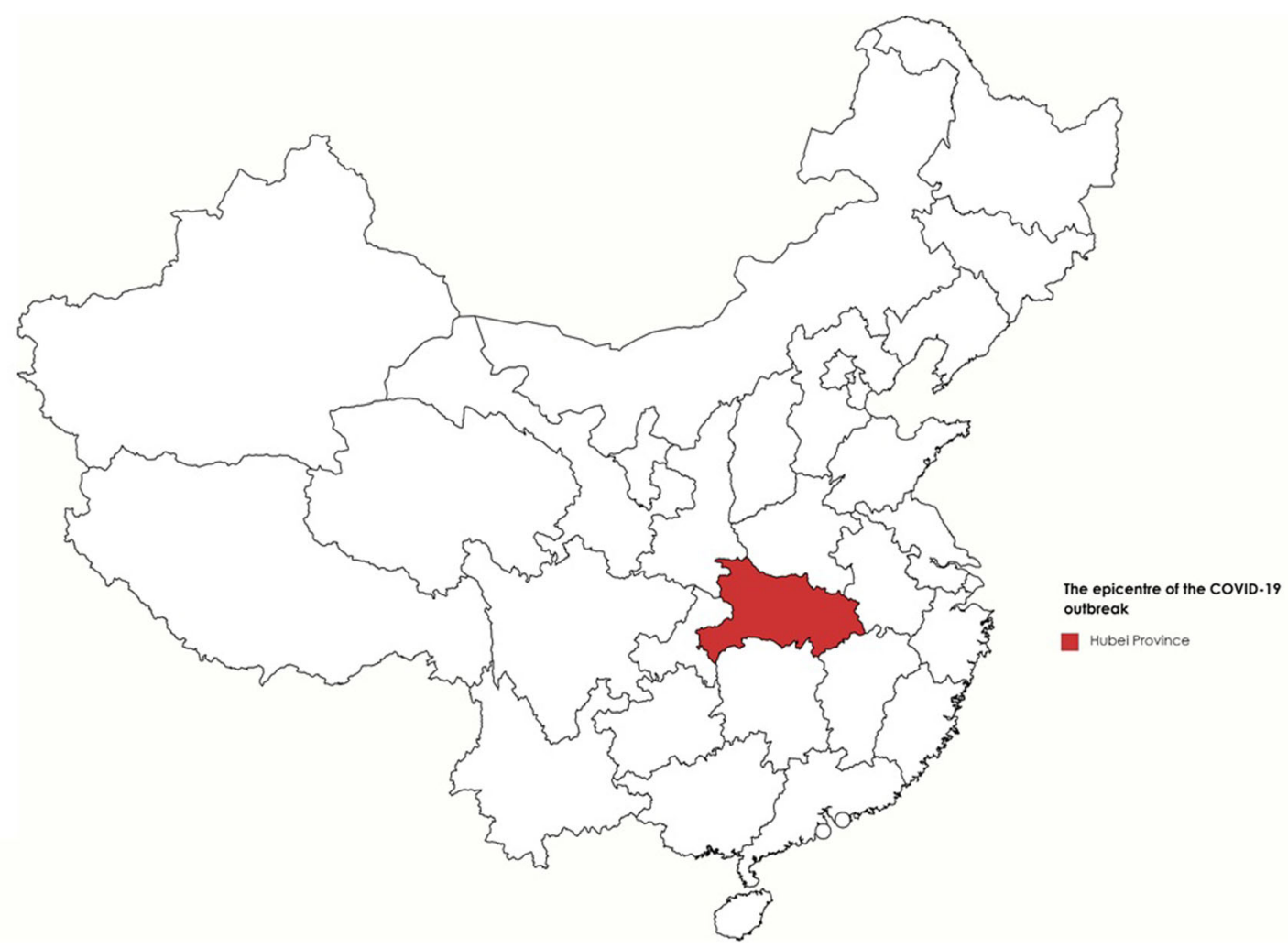

Fig. 1 The epicentre of COVID-19 outbreak

The two epidemics began in areas with populations with a preferences for consumption of wildlife (Sun et al. 2020), which has been identified as the source of both the outbreaks, and COVID-19 has been reported as having a probable origin in bats (Zhou et al. 2020). Viruses usually need intermediate hosts to spread from bats to humans (Sun et al. 2020), and some wildlife species such as pangolins are reported to act intermediate hosts of severe acute respiratory syndrome-coronavirus 2 (SARS-CoV-2). The virus may pass onto humans when they consume wildlife meat, and subsequently may lead to the risk of human-to-human transmission (Zhang et al. 2020).

However, published research related to the attitudes regarding the wildlife consumption during both the ongoing COVID-19 pandemic and the SARS outbreak of 17 years ago is very limited, illustrating the general lack of sufficient scientific attention to the safety of and attitudes towards consuming wildlife worldwide (Wei 2020). Therefore, our aim in this study was to determine changes in attitudes towards wildlife consumption in Chinese adults in relation to the SARS and COVID-19 outbreaks with a particular focus on Hubei Province. This is because Hubei Province, especially its capital city Wuhan, has been significantly hit by the COVID-19 pandemic. Our findings from this study have important implications for public health, especially relating to the current dietary habit of consuming wildlife meat in China and elsewhere, and provide a basis for future studies to develop more effective prevention and treatment strategies.

\section{Methods}

We conducted a cross-sectional study between 7 April 2020 and 20 April 2020 by using convenience sampling. Inclusion criteria included: non-pregnant individuals of Chinese nationality aged $\geq 18$ years and currently living either in or outside Hubei Province, China, who were living in same province during both the SARS and COVID-19 outbreaks. No financial rewards were given to participants for completing the questionnaire. All participants provided informed consent prior to the study enrolment. The study had obtained the approval from the Ethics Committee of the Jinzhou Medical University (ref. no. JYDLL2020002). In addition, our study protocol was conducted according to the provisions of the Declaration of Helsinki (as revised in Edinburgh 2000).

The questionnaire comprised a total of 20 related questions including 11 eliciting basic socioeconomic information such as sex, age, education, job type, marital status, religion, and city of residence. We also asked participants if their employment was related to healthcare professions. Additionally, participants were also asked to indicate whether they or their friends/relatives were currently diagnosed with COVID-19. There were five questions each for SARS and COVID-19. Furthermore, participants were asked what they would do if they see someone hunting illegally. The questionnaire was distributed via WeChat, QQ, and Baidu Post Bar. 


\section{Wildlife Consumption}

In the SARS and COVID-19 sections of the questionnaire, we asked participants whether they had ever eaten wildlife such as palm civets, snakes, wild boar, frogs, monkeys, bats, or pangolins during the outbreaks. If they answered yes, they were asked to select their reason for eating wildlife, including "I eat wildlife for nutrients," "I eat wildlife to test something novel," "I eat wildlife because they taste good," or "I eat wildlife because they are expensive, and they signify my social status." If they answered no, they were asked to select their reasons for not eating wildlife, including "I do not eat wildlife because I dislike eating wildlife," "I do not eat wildlife because they are protected by law," "I do not eat wildlife because they are too expensive," and "I do not eat wildlife because it is hard to buy wildlife in the local markets." We then provided four choices for participants reflecting whether or not their opinion had changed about eating wildlife since the SARS outbreak: "I eat wildlife whenever I get the chance," "I have stopped eating wildlife meats because wildlife are legally protected," "I will only eat wildlife meats after they are inspected by food inspectors," and "I had another reason," which they were asked to state specifically. We also included questions as to whether participants considered palm civets to be carriers of SARS, and bats to be carriers of SARS-CoV-2.

\section{Statistical Analysis}

Statistical analyses were performed using SPSS ver. 25 (SPSS, Chicago, IL). Differences were considered statistically significant when a $P$ value was $<0.05$. Difference between sex and age were determined using an independent t-test. A significant relationship between two categorical variables were analysed with a Chi-Square test. All results of quantitative variables were presented either as frequency (percentage) $(\%)$ or mean \pm standard deviation where appropriate.

\section{Results}

\section{Participant Characteristics}

The online questionnaire was completed by 348 Chinese adults and of these, $66.7 \%$ (231/348) were from Hubei Province and $35.3 \%$ (123/348) were from Wuhan city (Table 1). The mean age of participants was $29.4 \pm 8.5$, with no difference in mean age between men and women $(P=$ 0.873 ), and $95.7 \%$ of participants were under 50 years old. The majority of participants $(81.9 \%)$ had a higher education qualification level. About one third of participants (37.1\%) were married. None of the participants in the study was currently diagnosed with COVID-19; only two participants indicated that they had friends who had been diagnosed with
COVID-19; $92.0 \%$ of participants declared they had no religious belief, and $6.3 \%$ indicated they were Buddhist. In addition, $97.1 \%$ were of Han ethnicity, while Man and Hui accounted for $1.1 \%$ and $1.1 \%$, respectively.

\section{Wildlife Meat Consumption during SARS and COVID- 19}

The percentages of participants who had ever eaten wildlife were much lower than those who had not eaten, both during the SARS $(27.0 \%$ vs. $73.0 \%)$ and COVID-19 (17.8\% vs. $82.2 \%$ ) outbreaks (Tables 2 and 3). However, the percentages of participants who consumed wildlife differed significantly during two outbreaks $(P=0.032)$, as $27.0 \%$ of participants reported that they consumed wildlife before SARS and only $17.8 \%$ had eaten wildlife before COVID-19.

For those who had eaten wildlife, the most common reason was to test something novel, $64.9 \%$ during the SARS and $54.8 \%$ during the COVID-19 outbreaks, respectively. Interestingly, no one consumed wildlife because of the expense signified their social status. For those who had never eaten wildlife, the two most common reasons were dislike of eating wildlife $(47.7 \%$ during SARS and $39.9 \%$ during COVID-19) and because most species of wildlife are protected by law $(43.3 \%$ during SARS and $52.5 \%$ during COVID-19).

Education level was significantly associated with wildlife consumption, both during the SARS and COVID-19 outbreaks $(P=0.002$ and $P<0.001$, respectively). Additionally, only during the SARS outbreak, there were significant differences in the percentages of wildlife consumption between males and females $(10.5 \%$ and $42.9 \%$, respectively) $(\mathrm{P}<$ 0.001). However, there was no difference in the percentage of participants living inside or outside Hubei who consumed wildlife during the two outbreaks $(P=0.669$ and $P=0.620$, respectively).

\section{Change of Opinion about Eating Wildlife during SARS and COVID-19}

Overall, the majority of participants reported that during the COVID-19 outbreak they stopped eating wildlife and/or did not eat it because they were legally protected species $(67.0 \%)$, followed by "only eat inspected wildlife meat" (24.4\%) and "eat when got opportunity" (5.2\%) (Tables 2 and 4). Similarly, majority of participants reported that during the SARS outbreak, they stopped eating wildlife and/or did not eat it because they were legally protected species $(53.5 \%)$, followed by "only eat inspected wildlife meat" $(40.0 \%)$ and "eat when got opportunity" (2.9\%) (Tables 3 and 5). Those who chose "other reasons" indicated that their attitudes towards not eating wildlife had never changed (3.7\% during COVID-19 and 3.5\% during SARS). 
Table 1 Sociodemographic characteristics of participants

\begin{tabular}{|c|c|c|c|c|}
\hline & All $(n=348)$ & Females $(n=171)$ & Males $(n=177)$ & $P$ value \\
\hline Age (years) & $29.4 \pm 8.5$ & $29.5 \pm 8.9$ & $29.3 \pm 8.0$ & 0.873 \\
\hline \multicolumn{5}{|l|}{ Education level, n (\%) } \\
\hline Secondary school & $63(18.1)$ & $32(18.7)$ & $31(17.5)$ & \multirow[t]{2}{*}{0.771} \\
\hline Higher qualification & $285(81.9)$ & $139(81.3)$ & $146(82.5)$ & \\
\hline \multicolumn{5}{|l|}{ Marital status, n (\%) } \\
\hline Single/Divorced & $219(62.9)$ & $83(48.5)$ & $136(76.8)$ & \multirow[t]{2}{*}{$<0.001$} \\
\hline Married & $129(37.1)$ & $88(51.5)$ & $41(23.2)$ & \\
\hline \multicolumn{5}{|l|}{ Region, n (\%) } \\
\hline Hubei & $232(66.7)$ & $112(48.3)$ & $120(51.7)$ & \multirow[t]{2}{*}{0.649} \\
\hline Outside Hubei & $116(33.3)$ & $59(50.9)$ & $57(49.1)$ & \\
\hline \multicolumn{5}{|l|}{ Job type, n (\%) } \\
\hline Local company & $87(25.0)$ & $19(11.1)$ & $68(38.4)$ & \multirow[t]{6}{*}{$<0.001$} \\
\hline Foreign company & $33(9.5)$ & $21(12.3)$ & $12(6.8)$ & \\
\hline Government agency & $52(14.9)$ & $27(15.8)$ & $25(14.1)$ & \\
\hline Individual own business & $24(6.9)$ & $9(5.3)$ & $15(8.5)$ & \\
\hline Students & $97(27.9)$ & $66(38.6)$ & $31(17.5)$ & \\
\hline Others including unemployment & $55(15.8)$ & $29(17.0)$ & $26(14.7)$ & \\
\hline \multicolumn{5}{|l|}{ Healthcare professional, n (\%) } \\
\hline No & 347 (99.7) & $170(99.4)$ & $177(100.0)$ & \multirow[t]{2}{*}{0.308} \\
\hline Yes & $1(0.3)$ & $1(0.6)$ & $0(0.0)$ & \\
\hline \multicolumn{5}{|l|}{ Religion, n (\%) } \\
\hline No & $320(92.0)$ & $153(89.5)$ & $167(94.4)$ & \multirow[t]{2}{*}{0.095} \\
\hline Yes & $28(8.0)$ & $18(10.5)$ & $10(5.6)$ & \\
\hline \multicolumn{5}{|l|}{ Ethnicity, n (\%) } \\
\hline Han & $338(97.1)$ & $164(95.9)$ & $174(98.3)$ & \multirow[t]{4}{*}{0.066} \\
\hline Man & $4(1.1)$ & $4(2.3)$ & $0(0.0)$ & \\
\hline Hui & $4(1.1)$ & $3(1.8)$ & $1(0.6)$ & \\
\hline Others & $2(0.6)$ & $0(0.0)$ & $2(1.1)$ & \\
\hline
\end{tabular}

There were significant differences in the perceptions of eating wildlife during SARS and COVID-19 between participants living in Hubei and those living outside Hubei $(P=$ 0.007 and $<0.001$, respectively) (Tables 4 and 5).
Participants living in Hubei indicated that they changed their opinion during SARS mainly because wildlife were legally protected $(59.1 \%)$, followed by "only eat inspected wildlife meat" (35.8\%), and "eat when got opportunity" (3.4\%).

Table 2 Wildlife consumption during the COVID-19 period by sex and age group

\begin{tabular}{|c|c|c|c|c|c|c|}
\hline & \multicolumn{2}{|l|}{$\operatorname{Sex}(n=348)$} & \multirow[t]{2}{*}{$P$ value } & \multicolumn{2}{|c|}{ Age group (years) $(n=348)$} & \multirow[t]{2}{*}{$P$ value } \\
\hline & Females $(n=171)$ & Males $(n=177)$ & & $<\mathbf{5 0}(n=\mathbf{3 3 3})$ & $\geq 50(n=15)$ & \\
\hline \multicolumn{7}{|l|}{ Consumption of wildlife meat, $\mathrm{n}(\%)$} \\
\hline $\begin{array}{l}\text { Yes } \\
\text { No }\end{array}$ & $\begin{array}{r}31(18.1) \\
140(81.9)\end{array}$ & $\begin{array}{r}31(17.5) \\
146(82.5)\end{array}$ & 0.881 & $\begin{array}{r}61(18.3) \\
272(81.7)\end{array}$ & $\begin{array}{c}1(6.7) \\
14(93.3)\end{array}$ & 0.249 \\
\hline \multicolumn{7}{|l|}{ Change of opinion about eating wildlife, $\mathrm{n}(\%)$} \\
\hline $\begin{array}{l}\text { Eat wildlife whenever they get the chance } \\
\text { Stop eating because they are legally protected } \\
\text { Only eat wildlife meats after they are inspected } \\
\text { Others }\end{array}$ & $\begin{aligned} 8 & (4.7) \\
112 & (65.5) \\
43 & (25.1) \\
8 & (4.7)\end{aligned}$ & $\begin{aligned} 10 & (5.6) \\
121 & (68.4) \\
42 & (23.7) \\
4 & (2.3)\end{aligned}$ & 0.612 & $\begin{aligned} 18 & (5.4) \\
221 & (66.4) \\
83 & (24.9) \\
11 & (3.3)\end{aligned}$ & $\begin{array}{c}0(0.0) \\
12(80.0) \\
2(13.3) \\
1(6.7)\end{array}$ & 0.481 \\
\hline \multicolumn{7}{|l|}{ Bats were the carriers of SARS, $n(\%)$} \\
\hline $\begin{array}{l}\text { Yes } \\
\text { No }\end{array}$ & $\begin{array}{l}94(55.0) \\
77(45.0)\end{array}$ & $\begin{array}{r}53(29.9) \\
124(70.1)\end{array}$ & $<0.001$ & $\begin{array}{l}142(42.6) \\
191(57.4)\end{array}$ & $\begin{array}{r}5(33.3) \\
10(66.7)\end{array}$ & 0.475 \\
\hline
\end{tabular}


Table 3 Wildlife consumption during the SARS period by sex and age group

\begin{tabular}{|c|c|c|c|c|c|c|}
\hline & \multicolumn{2}{|l|}{$\operatorname{Sex}(n=348)$} & \multirow[t]{2}{*}{ P value } & \multicolumn{2}{|c|}{ Age group (years) $(n=348)$} & \multirow[t]{2}{*}{$P$ value } \\
\hline & Females $(n=171)$ & Males $(n=177)$ & & $<50(n=333)$ & $\geq 50(n=15)$ & \\
\hline \multicolumn{7}{|l|}{ Consumption of wildlife meat, $\mathrm{n}(\%)$} \\
\hline $\begin{array}{l}\text { Yes } \\
\text { No }\end{array}$ & $\begin{array}{r}18(10.5) \\
153(89.5)\end{array}$ & $\begin{array}{r}76(42.9) \\
101(57.1)\end{array}$ & $<0.001$ & $\begin{array}{r}91(27.3) \\
242(72.7)\end{array}$ & $\begin{array}{r}3(20.0) \\
12(80.0)\end{array}$ & 0.532 \\
\hline \multicolumn{7}{|l|}{ Change of opinion about eating wildlife, $\mathrm{n}(\%)$} \\
\hline $\begin{array}{l}\text { Eat wildlife whenever they get the chance } \\
\text { Stop eating because they are legally protected } \\
\text { Only eat wildlife meats after they are inspected } \\
\text { Others }\end{array}$ & $\begin{array}{c}6(3.5) \\
98(57.3) \\
58(33.9) \\
9(5.3)\end{array}$ & $\begin{array}{c}4(2.3) \\
88(49.7) \\
81(45.8) \\
4(2.3)\end{array}$ & 0.087 & $\begin{array}{c}9(2.7) \\
177(53.2) \\
135(40.5) \\
12(3.6)\end{array}$ & $\begin{array}{l}1(6.7) \\
9(60.0) \\
4(26.7) \\
1(6.7)\end{array}$ & 0.58 \\
\hline \multicolumn{7}{|l|}{ Palms civets were the carriers of SARS, $\mathrm{n}(\%)$} \\
\hline $\begin{array}{l}\text { Yes } \\
\text { No }\end{array}$ & $\begin{array}{l}91(53.2) \\
80(46.8)\end{array}$ & $\begin{array}{l}94(53.1) \\
83(46.9)\end{array}$ & 0.984 & $\begin{array}{l}178(53.5) \\
155(46.5)\end{array}$ & $\begin{array}{l}7(46.7) \\
8(53.3)\end{array}$ & 0.606 \\
\hline
\end{tabular}

However, when it came to the COVID-19 outbreak, the percentages changed to $64.7 \%, 26.7 \%$, and $6.9 \%$, respectively. Participants outside Hubei changed their opinion to "only eat inspected wildlife meat" (48.3\%), followed by stop eating wildlife because they were legally protected $(42.2 \%)$, and "eat when got opportunity" (1.7\%) during SARS. These percentages changed to $19.8 \%$ ("only eat inspected wildlife meat"), $71.6 \%$ ("stop eating wildlife were legally protected"), and $1.7 \%$ ("eat when got opportunity"), respectively during COVID-19.

There were significant differences in the perceptions of eating wildlife between participants who had higher educational qualifications and participants with secondary education level during SARS and COVID-19. The percentages of them choosing "stop eating wildlife were legally protected", "only eat inspected wildlife meat" and "eat when got opportunity" were $47.0 \%, 46.3 \%$, and $2.8 \%$ respectively for participants who had higher educational qualifications compared to $82.5 \%, 11.1 \%$, and $3.2 \%$ for participants with secondary education level, respectively, during SARS. On the other hand, the percentages of those choosing "stop eating because wildlife were legally protected," "only eat inspected wildlife meat," and "eat when got opportunity" were $72.6 \%, 18.9 \%$ and $4.9 \%$ for participants who had higher education compared to $41.3 \%, 49.2 \%$ and $6.3 \%$ for participants with secondary education, respectively during COVID-19 (all $P<0.001$ ). There were no differences in the percentages of those changing of their opinion about eating wildlife between males and females and different age groups during COVID-19 and SARS (all $P>0.05$ ).

Table 4 Wildlife consumption during the COVID-19 period by education level and regions

\begin{tabular}{|c|c|c|c|c|c|c|}
\hline & \multicolumn{2}{|c|}{ Education level $(n=348)$} & \multirow{2}{*}{$\begin{array}{l}P \\
\text { value }\end{array}$} & \multicolumn{2}{|c|}{ Regions $(n=348)$} & \multirow{2}{*}{$\begin{array}{l}P \\
\text { value }\end{array}$} \\
\hline & $\begin{array}{l}\text { Secondary school } \\
(n=63)\end{array}$ & $\begin{array}{l}\text { Higher qualification } \\
(n=285)\end{array}$ & & $\begin{array}{l}\text { Hubei } \\
(n=231)\end{array}$ & $\begin{array}{l}\text { Outside Hubei } \\
(n=117)\end{array}$ & \\
\hline \multicolumn{7}{|l|}{ Consumption of wildlife meat, $\mathrm{n}(\%)$} \\
\hline $\begin{array}{l}\text { Yes } \\
\text { No }\end{array}$ & $\begin{array}{l}25(39.7) \\
38(60.3)\end{array}$ & $\begin{array}{r}37(13.0) \\
248(87.0)\end{array}$ & $<0.001$ & $\begin{array}{r}43(18.5) \\
189(81.5)\end{array}$ & $\begin{array}{l}19(16.4) \\
97(83.6)\end{array}$ & 0.620 \\
\hline \multicolumn{7}{|c|}{ Change of opinion about eating wildlife, $\mathrm{n}(\%)$} \\
\hline $\begin{array}{l}\text { Eat wildlife whenever they get the } \\
\text { chance }\end{array}$ & $4(6.3)$ & $14(4.9)$ & \multirow[t]{4}{*}{$<0.001$} & $16(6.9)$ & $2(1.7)$ & \multirow[t]{4}{*}{0.007} \\
\hline $\begin{array}{l}\text { Stop eating because they are legally } \\
\text { protected }\end{array}$ & $26(41.3)$ & $207(72.6)$ & & $150(64.7)$ & $83(71.6)$ & \\
\hline $\begin{array}{l}\text { Only eat wildlife meats after they are } \\
\text { inspected }\end{array}$ & $31(49.2)$ & $54(18.9)$ & & $62(26.7)$ & $23(19.8)$ & \\
\hline Others & $2(3.2)$ & $10(3.5)$ & & $4(1.7)$ & $8(6.9)$ & \\
\hline \multicolumn{7}{|l|}{ Bats were the carriers of SARS, n (\%) } \\
\hline Yes & $27(42.9)$ & $120(42.1)$ & \multirow[t]{2}{*}{0.913} & $94(40.5)$ & $53(45.7)$ & \multirow[t]{2}{*}{0.357} \\
\hline No & $36(57.1)$ & $165(57.9)$ & & $138(59.5)$ & $63(54.3)$ & \\
\hline
\end{tabular}


Table 5 Wildlife consumption during the SARS period by education level and regions

\begin{tabular}{|c|c|c|c|c|c|c|}
\hline & \multicolumn{2}{|c|}{ Education level $(n=348)$} & \multirow{2}{*}{$\begin{array}{l}P \\
\text { value }\end{array}$} & \multicolumn{2}{|c|}{ Regions $(n=348)$} & \multirow{2}{*}{$\begin{array}{l}P \\
\text { value }\end{array}$} \\
\hline & $\begin{array}{l}\text { Secondary school } \\
(n=63)\end{array}$ & $\begin{array}{l}\text { Higher qualification } \\
(\mathrm{n}=\mathbf{2 8 5})\end{array}$ & & $\begin{array}{l}\text { Hubei } \\
(\mathrm{n}=\mathbf{2 3 1})\end{array}$ & $\begin{array}{l}\text { Outside Hubei } \\
(\mathrm{n}=117)\end{array}$ & \\
\hline \multicolumn{7}{|l|}{ Consumption of wildlife meat, $\mathrm{n}(\%)$} \\
\hline $\begin{array}{l}\text { Yes } \\
\text { No }\end{array}$ & $\begin{array}{r}7(11.1) \\
56(88.9)\end{array}$ & $\begin{array}{r}87(30.5) \\
198(69.5)\end{array}$ & 0.002 & $\begin{array}{r}61(26.3) \\
171(73.7)\end{array}$ & $\begin{array}{l}33(28.4) \\
83(71.6)\end{array}$ & 0.669 \\
\hline \multicolumn{7}{|c|}{ Change of opinion about eating wildlife, n (\%) } \\
\hline $\begin{array}{l}\text { Eat wildlife whenever they get the } \\
\text { chance }\end{array}$ & $2(3.2)$ & $8(2.8)$ & \multirow[t]{4}{*}{$<0.001$} & $8(3.4)$ & $2(1.7)$ & \multirow[t]{4}{*}{0.001} \\
\hline $\begin{array}{l}\text { Stop eating because they are legally } \\
\text { protected }\end{array}$ & $52(82.5)$ & $134(47.0)$ & & $137(59.1)$ & $49(42.2)$ & \\
\hline $\begin{array}{l}\text { Only eat wildlife meat after they are } \\
\text { inspected }\end{array}$ & $7(11.1)$ & $132(46.3)$ & & $83(35.8)$ & $56(48.3)$ & \\
\hline Others & $2(3.2)$ & $11(3.9)$ & & $4(1.7)$ & $9(7.8)$ & \\
\hline \multicolumn{7}{|c|}{ Palms civets were the carriers of SARS, n (\%) } \\
\hline $\begin{array}{l}\text { Yes } \\
\text { No }\end{array}$ & $\begin{array}{l}15(23.8) \\
48(76.2)\end{array}$ & $\begin{array}{l}170(59.6) \\
115(40.4)\end{array}$ & $<0.001$ & $\begin{array}{l}111(47.8) \\
121(52.2)\end{array}$ & $\begin{array}{l}74(63.8) \\
42(36.2)\end{array}$ & 0.005 \\
\hline
\end{tabular}

\section{Carriers of Coronaviruses and Attitudes towards Illegal Hunting}

More than half of the participants $(53.7 \%)$ thought that palm civets were carriers of SARS, while only $14.7 \%$ indicated they did not think that palm civets were carriers of SARS, and about one-third $(32.2 \%)$ indicated they did not know. In addition, nearly half the participants $(42.2 \%)$ agreed that bats were carriers of SARS-CoV-2. Furthermore, significantly more female participants agreed that bats were carriers of SARS-CoV-2 than male participants (55.0\% vs. 29.9\%) (P $<0.001$ ) (Table 2). In response to the question asking what they would do if they saw somebody hunting illegally, $26.7 \%$ of participants reported that they would determine to stop it, $64.4 \%$ would try to stop it, and only $8.9 \%$ would ignore it.

\section{Discussion}

Our study results clearly indicate that Chinese attitudes towards eating wildlife have changed significantly between the 20022003 SARS outbreak and the December 2019 ongoing COVID-19 outbreak. The percentages of participants who had eaten wildlife decreased from $27.0 \%$ during SARS to $17.8 \%$ during COVID-19 $(P=0.032)$. This showed that the Chinese population's attitudes towards eating wildlife have significantly altered over the past 17 years, which may be due to the fact that SARS outbreak encouraged greater vigilance and reflection on the dangers inherent in wildlife meat consumption. In addition, there are currently many non-governmental organizations organizing activities to further protect wildlife (Yuan et al. 2020).

There were significant differences in opinions about eating wildlife during SARS and COVID-19 between participants from Hubei and participants outside Hubei. Approximately three-fifths of participants from Hubei chose not to eat wildlife because most wildlife species are legally protected. Approximately half of participants outside Hubei chose only to eat inspected wildlife meat. From the SARS outbreak to the COVID-19 outbreak, the changes in the opinion of participants from Hubei and outside Hubei were reflected in the fact that the participants who only consumed wildlife that had been inspected during SARS indicated that they stopped eating wildlife during COVID-19. Only $47.8 \%$ of participants from Hubei agreed that palm civets were carriers of the SARS virus, which was lower than those participants outside Hubei $(63.8 \%)(P=0.005)$. This may be because since the main outbreak area of SARS was not concentrated in Hubei so that of outbreak may not have had such a profound impact among participants from Hubei (Evans et al. 2003).

In addition, our results indicate that education level significantly affected attitudes towards wildlife consumption. Interestingly, during SARS, $30.5 \%$ of participants with higher education qualifications indicated they consumed wildlife, which was more than twice that of participants without higher education $(11.1 \%)(P=0.002)$. The percentages of participants with higher education who thought that palm civets were SARS carriers were more than twice as high as those without higher education $(P<0.001)$. However, during COVID-19, the percentages of participants with secondary school education who consumed wildlife were three times that of participants with higher education. At the same time, these two groups also reflected significant changes in perceptions of eating wildlife $(\mathrm{P}<0.001)$. From SARS to COVID-19, participants with higher education who indicated they chose to "stop eating because wildlife are legally protected" increased from $47.0 \%$ to $72.6 \%$. Usually, wildlife meat is sold for higher 
prices because of its scarcity. Consumers with higher income and higher education level were reported to have higher consumption rates of wild animals (Zhang and Yin 2014). Additionally, consumers with higher education levels usually have a higher income. Therefore, this may explain why there were higher percentages of participants with higher education levels who consumed wild meat than those with secondary education level during SARS (30.5\% vs. $11.1 \%$ ). However, during COVID-19, there were fewer participants with higher education who consumed wildlife than those with secondary level education. It is possible that participants with higher education levels might have become more aware of the risks associated with wildlife consumption, especially after SARS and COVID-19.

China's per capita consumption of meat quadrupled from 1978 to 2002 (Liu and Diamond 2005). However, meat production cannot keep up with China's growing appetite for animal products cannot (Machovina et al. 2015). Eating wildlife may be a way to increase sources of protein (Asibey 1974). The consumption of wildlife is not uncommon in many parts of the world, including America, Africa, and Asia, and in many cases is a very important part of cultural identify (Lindsey et al. 2013; Volpato et al. 2020). However, the Chinese population currently have abundant choices for sources of protein. In our study, more than half of the participants indicated that they ate wildlife meat because they wanted to try something novel, and secondly that they like its taste. Only a small number of participants (16.0\% during SARS and 9.7\% during COVID-19) thought that wildlife meat has special nutritional value. This seems to indicate that wildlife meat rather than being a necessary source of protein for the Chinese population is nowadays simply a matter of personal choice. It is worth noting that during the two outbreaks, none of the participants reported that they consumed wildlife because the expensive price signified their social status. If laws related to the protection of wildlife are tightened and strictly enforced, and cutting off the supply of wildlife in markets, then the cost of eating illegally hunted wildlife will increase. The Chinese population will then find it increasingly difficult to find opportunities to consume wildlife. Thus, the number of individuals who eat wildlife to satisfy their curiosity would also be greatly reduced. At the same time, the dangers inherent in the consumption of wildlife meat, especially if the source is unknown, should be widely publicized. As has become clear during the ongoing COVID-19 outbreak, some species of wildlife carry viruses that can cross barriers between species and mutate to become dangerous and potentially fatal to humans (Volpato et al. 2020). Also noteworthy is that more than half of our study participants $(53.7 \%)$ indicated that they thought that palm civets were carriers of SARS. However, fewer than half of the participants $(42.2 \%)$ thought that bats were the carriers of SARS-CoV-2. This may be because, at the time the questionnaire was circulated, the
COVID-19 outbreak was so recent. When compared to the SARS outbreak of 17 years ago, participants may not have had enough knowledge and familiarity with COVID-19.

However, since the habit of consuming wildlife is acquired over a long period, a gradual approach to improving eating habits should be adopted, since it is neither feasible to force the Chinese population to change their dietary habits just after the pandemic outbreak, nor would it likely produce the desired outcomes. In our study, some participants reported that they would continue to consume wildlife meat, which indicates that there is still demand for wildlife meat. After the COVID-19 outbreak, Chinese government shut down wet markets (markets for live or freshly slaughtered animals), but this clearly did not eliminate demand, and may in fact lead to the wildlife trade continuing underground (Volpato et al. 2020). It is more realistic to provide a greater variety of food choices in the markets. For example, most of our study participants (64.9\% during the SARS and 54.8\% during the ongoing COVID-19 outbreaks, respectively) consumed wildlife meat because they felt that the wildlife meat was novel and they had the opportunity to acquire it. If qualified enterprises can breed some of these wild species, with the same safety guarantees as currently domesticated farm animals, this could provide an alternative safe option for those who continue to favour wildlife consumption. It might be easier to achieve with better results rather than attempting to enforce a blanket ban on wildlife consumption. Furthermore, while protecting the original environment of endangered wildlife species is important, intensive breeding for reintroduction or even meat production is also a useful strategy (LeaderWilliams et al. 1991). The Chinese government has in fact implemented a series of measures, including amending the wildlife protection law and captive breeding of wildlife, to further enhance wildlife protection (Wang et al. 2019).

It was encouraging that the majority of our study participants $(91.1 \%)$ indicated that they would stop or try to stop illegal hunting, with more than a quarter saying they would firmly stop illegal hunters, and only $8.9 \%$ indicated they would not take any action. The COVID-19 outbreak has led to lockdown for months, greatly affecting the lives of the whole nation and the whole world (Yuan et al. 2020). It is hoped that the serious consequences of this COVID-19 pandemic will alert the Chinese population to the importance of environmental protections.

A significant strength of our study is that it is one of the first to investigate the impact of COVID-19 on wildlife consumption and compare the results with the earlier SARS outbreak. Furthermore, since we especially targeted participants from Hubei Province, and more than a half of the Hubei participants were living in Wuhan, the epicentre of the COVID-19 outbreak, we had the opportunity to determine whether there were differences in the attitudes of wildlife consumption between residents from both inside and outside the epicentre of the COVID-19 outbreak. One limitation of our study is potential recall bias, because participants might have had difficulty 
recalling details from the SARS period 17 years ago. Another limitation is the use of the convenience sampling method. In addition, the translation of some English words and Western understandings such as "wildlife" could be problematic in China because of different historical rationales for eating wildlife in Chinese and Western conceptions and cultures. Therefore, our findings should be interpreted cautiously.

In conclusion, in the 17 years from the SARS to COVID19 outbreaks, the proportion of Chinese adults consuming wildlife has decreased significantly. At present, Chinese populations seem to be in favour stopping wildlife consumption and fighting against illegal hunting. However, it is likely that some people in China will continue to consume wildlife meat for a number of reasons including believed health benefits.

Author's Contributions Conceptualization, Shuchang Liu, Zheng Feei Ma, Yutong Zhang and Yingfei Zhang; Formal analysis, Shuchang Liu, Zheng Feei Ma, Yutong Zhang and Yingfei Zhang; Methodology, Shuchang Liu, Zheng Feei Ma, Yutong Zhang and Yingfei Zhang; Writing - original draft, Shuchang Liu and Zheng Feei Ma; Writing review and editing, Shuchang Liu, Zheng Feei Ma, Yutong Zhang and Yingfei Zhang.

Funding This research did not receive any specific grant from funding agencies in the public, commercial, or not-for-profit sectors.

Data Availability The datasets generated during and/or analysed during the current study are available from the corresponding author on reasonable request.

\section{Compliance with Ethical Standards}

Conflict of Interest The authors declare that they have no conflict of interest.

Informed Consent The present study was approved by Jinzhou Medical University Research Ethics Committee involving human beings. (ref. no. JYDLL2020002). In addition, our study protocol was conducted according to the provisions of the Declaration of Helsinki (as revised in Edinburgh 2000). All participants were briefed about the study protocol and informed consent was obtained from them.

\section{References}

Asibey, E.O.A. (1974). Wildlife as a source of protein in Africa South of the Sahara. Biological Conservation, 6, 32-39.

Cao, Y. et al. (2020). Evaluation of lifestyle, attitude and stressful impact amid the COVID-19 pandemic among adults in Shanghai, China. International Journal of Environmental Health Research. https:// doi.org/10.1080/09603123.2020.1841887.

Dong, E., Du, H. \& Gardner, L. (2020). An interactive web-based dashboard to track COVID-19 in real time. Lancet Infectious Diseases, 20, 533-534.

Evans, M.R., Xu, R.H., He, J.F. \& Peng, G.W. (2003). Epidemiologic clues to SARS origin in China. Emerging Infectious Diseases, 10, 1030.

Leader-Williams, N., Hudson, R.J., Drew, K.R. \& Baskin, L.M. (1991). Wildlife production systems: Economic utilisation of wild ungulates. Journal of Animal Ecology, 60, 372.
Li, P.J. \& Davey, G. (2013). Culture, reform politics, and future directions: A review of China's animal protection challenge. Society and Animals, 21, 34-53.

Lindsey, P.A. et al. (2013). The bushmeat trade in African savannas: Impacts, drivers, and possible solutions. Biological Conservation, $160,80-96$.

Liu, J. \& Diamond, J. (2005). China's environment in a globalizing world. Nature, 435, 1179-1186.

Lu, H., Stratton, C.W. \& Tang, Y.W. (2020). Outbreak of pneumonia of unknown etiology in Wuhan, China: The mystery and the miracle. Journal of Medical Virology, 92, 401-402.

Ma, Z.F. et al. (2020). Increased stressful impact among general population in mainland China amid the COVID-19 pandemic: a nationwide cross-sectional study after Wuhan city's travel ban lifted. International Journal of Social Psychiatry, doi:https://doi.org/10. 1177/0020764020935489.

Machovina, B., Feeley, K.J. \& Ripple, W.J. (2015). Biodiversity conservation: The key is reducing meat consumption. Science of The Total Environment, 536, 419-431.

Maier, B.F. \& Brockmann, D. (2020). Effective containment explains sub-exponential growth in confirmed cases of recent COVID-19 outbreak in mainland China. Science, 368, 742-746.

Sun, Z., Thilakavathy, K., Kumar, S.S., He, G. \& Liu, S.V. (2020). Potential factors influencing repeated SARS outbreaks in China. International Journal of Environmental Research and Public Health, 17, 1633.

Volpato, G., Fontefrancesco, M.F., Gruppuso, P., Zocchi, D.M. \& Pieroni, A. (2020). Baby pangolins on my plate: possible lessons to learn from the COVID-19 pandemic. Journal of Ethnobiology and Ethnomedicine, 16, 19.

Wang, W. et al. (2019). Captive breeding of wildlife resources-China's revised supply-side approach to conservation. Wildlife Society Bulletin, 43, 425-435.

Wei, G. (2020). Food safety issues related to wildlife have not been taken seriously from SARS to COVID-19. Environmental Research, 186, 109605.

$\mathrm{Wu}$, F. et al. (2020). A new coronavirus associated with human respiratory disease in China. Nature, 579, 265-269.

Yuan, J., Lu, Y., Cao, X. \& Cui, H. (2020). Regulating wildlife conservation and food safety to prevent human exposure to novel virus. Ecosystem Health and Sustainability, 6, 1741325.

Zhang, L. \& Yin, F. (2014). Wildlife consumption and conservation awareness in China: a long way to go. Biodiversity and Conservation, 23, 2371-2381.

Zhang, Y. \& Ma, Z.F. (2020a). Impact of the COVID-19 pandemic on mental health and quality of life among local residents in Liaoning Province, China: a cross-sectional study. International Journal of Environmental Research and Public Health, 17.

Zhang, Y. \& Ma, Z.F. (2020b). Psychological responses and lifestyle changes among pregnant women with respect to the early stages of COVID-19 pandemic. International Journal of Social Psychiatry. https://doi.org/10.1177/0020764020952116.

Zhang, Y. et al. (2020). Willingness of the general population to accept and pay for COVID-19 vaccination during the early stages of COVID-19 pandemic: a nationally representative survey in mainland China. Human Vaccines and Immunotherapeutics. https://doi. org/10.1080/21645515.2020.1847585.

Zhong, N.S. et al. (2003). Epidemiology and cause of severe acute respiratory syndrome (SARS) in Guangdong, People's Republic of China, in February, 2003. Lancet, 362, 1353-1358.

Zhou, P. et al. (2020). A pneumonia outbreak associated with a new coronavirus of probable bat origin. Nature, 579, 270-273.

Publisher's Note Springer Nature remains neutral with regard to jurisdictional claims in published maps and institutional affiliations. 